\title{
MATURITY OF PROJECT MANAGEMENT IN POLISH AND FOREIGN CONSTRUCTION COMPANIES
}

\author{
Jarosław GÓRECKI \\ University of Technology and Life Sciences in Bydgoszcz \\ Faculty of Civil and Environmental Engineering and Architecture \\ Department of Construction Engineering and Management, Bydgoszcz, Poland \\ e-mail: gorecki@utp.edu.pl
}

\begin{abstract}
The paper describes a problem of project maturity of Polish and foreign construction companies. They were analyzed by their ability to execute construction investment projects. Survey results refer to issues related to the organizational culture and challenges connected with an improvement of the processes of project management for construction. Generation $\mathrm{Y}$ employees, their value, and their role at work were discussed in particular. It was underlined that modern managers should be able to profit from skills of Generation Y and to employ and retain the best of them in order to build a competitive advantage of the company. It was revealed that a success of the company is connected with an increasing level of project maturity as a condition for a successful project management.
\end{abstract}

Keywords: construction companies, project maturity, risk management, Generation Y.

\section{Introduction}

A specificity of the construction as a unique industry evokes a necessity for considering construction investment projects with paying special attention to their attributes that have various origins. Those constraints, no matter if we call them The Iron Triangle [1], The Golden Triangle [2], more accurately - The Project Management Triangle [3, p. 8; 4, p. 22; 5] or more complex - The Project Management Diamond [6, p. 471], or even by any other names of the concept based on six or more variables, that is, scope, schedule, budget, risk, resources, and quality, they always become crucial features of a project. It is obvious that a specific project will influence the constraints so a project manager needs to be focused on them. It has to be said that the project team must be able to assess the situation and balance the demands in order to ensure a successful project [7, p. 7].

Construction investment projects consist in spending money on creating new or additional assets that a company intends to convert into future benefits. A typical goal of this kind of projects is to build/construct, renovate, or improve a building or an infrastructure that is a result of the project. Owing to a scale of the construction project, its physical dimensions and, therefore, a long-term work that occurs in one location with a duration of, on an aver- age, more than one year, management should be careful about achieving project's goals that are prone to error caused by poor project planning.

Risk, which is in fact a definition of the situation mentioned above, is a key factor of the successful project [8, pp. 18-27; 9]. The authors underline that taking into consideration a risk perspective in the management can be vital for the organization and can become an important condition for business growth. According to some studies [9], there is a specific relationship between a success of a project and a success of an enterprise. Moreover, it was revealed that there is a connection between a success of construction enterprises and their successful investment, construction projects [10, pp. 278-285].

It is worth to emphasize that construction projects are complex and associated with many uncertainties. According to some papers, these uncertainties come from not only the unique nature of the project but also the diversity of required resources and activities. In general, they lead to a risk (what was noticed previously) in achieving two main objectives (schedule and budget) that might cause conflicts between owners and contractors where claims arise [11, pp. 20-29].

A response to the need for eliminating uncertainties and reducing risks coming from economic activity is an attempt to improve project management capabili- 
ties in a company. That is why construction companies should pay more and more attention frequently to the phenomenon called project maturity.

\section{Maturity of construction project manage- ment in Polish construction companies}

Before marking project maturity as an important factor, it must be explained what does it mean.

In fact, maturity can be defined as a quality or a state of being mature. If a concept of maturity is applied to an organization, it may refer to a state where an organization is in a perfect condition to achieve its objectives. Consequently, project maturity can mean that an organization is perfectly conditioned to deal with its projects [12]. It seems to be quite obvious to talk about a certain degree of maturity and make an effort to measure or characterize the maturity of the organization because fully matured organization is just a theoretical concept.

A narrower concept of project maturity is presented by some other scientists. For example, maturity of risk management in large-scale construction projects and therefore models based on this phenomenon can effectively help organizations to understand the level of current practice in terms of their capabilities in risk management, as well as their strengths and weaknesses toward future risk management practice, in order to take appropriate actions to improve their risk management performances [13].

According to Deloitte's report, "construction companies rate the maturity of construction project management relatively high, and therefore a great number of organizations are well prepared for worsening market conditions" [14].

Deloitte's researchers examined in 2012 all answers received from 39 Polish construction companies that operate countrywide. Those companies were classified by three factors: revenue generated in 2010 in PLN, capital origin, and the presence on the Warsaw Stock Exchange. A structure of the sample is presented in Fig. 1-3.

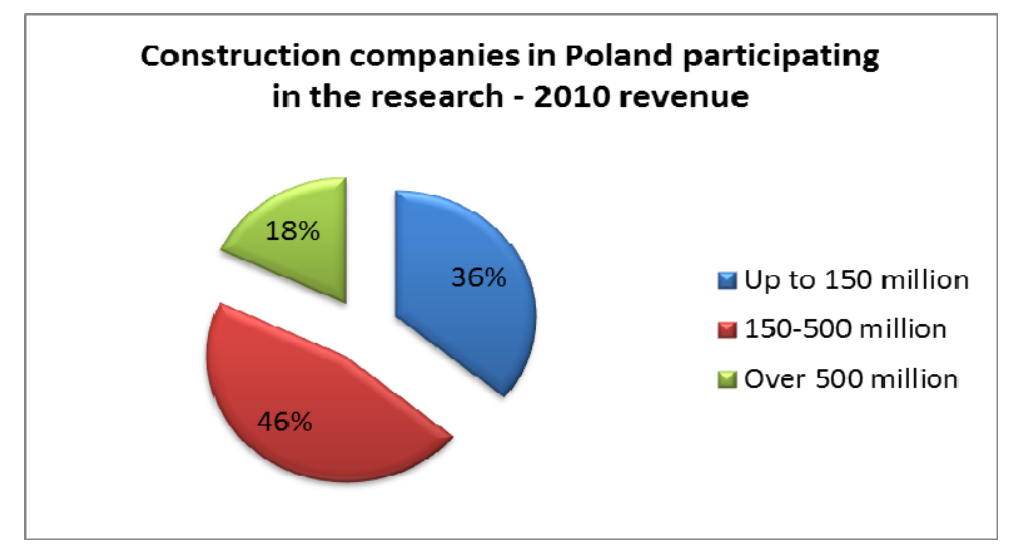

Figure 1. Sample structure by revenue generated in 2010 in PLN [14]

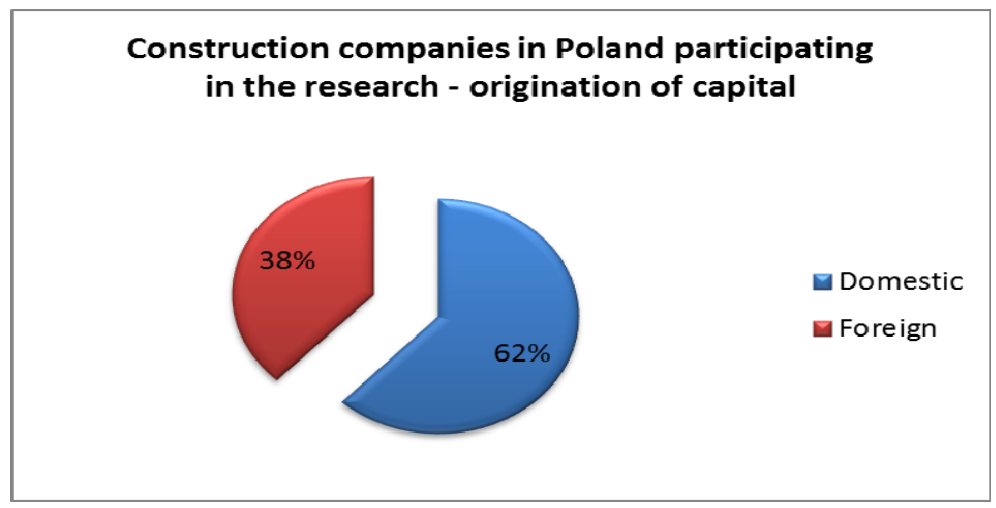

Figure 2. Sample structure by origination of capital [14] 


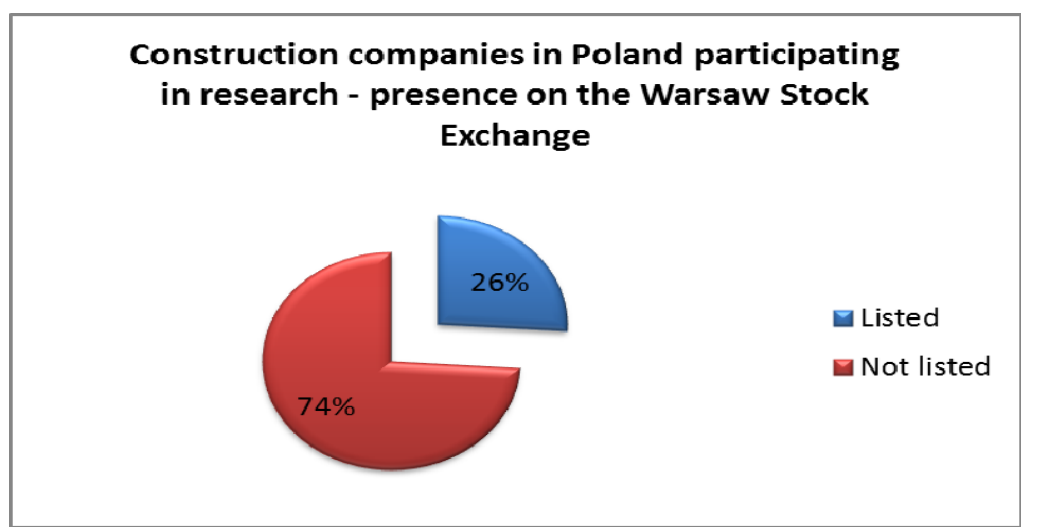

Figure 3. Sample structure by presence on the WSE [14]

Organizations that participated in the survey were asked to indicate a maturity level for 13 project management knowledge areas (according to the PMBoK methodology), that is, Project Integration Management, Project Scope Management, Project Time Management, Project Cost Management, Project Quality Management, Project Human Resource Management, Project Communication Management, Project Risk Management, Project Procurement Management, Project Environmental Management,
Project Financial Management, Project Safety Management, and Project Claim Management.

According to the report, a concept of maturity refers to the comparative level of advancement that an organization has regarding any given activity or sets of activities. Organizations with more fully defined and actively used policies, standards, and practices are considered more mature than the others. All respondents indicated one out of five maturity levels described in the following for each knowledge area (Fig. 4).

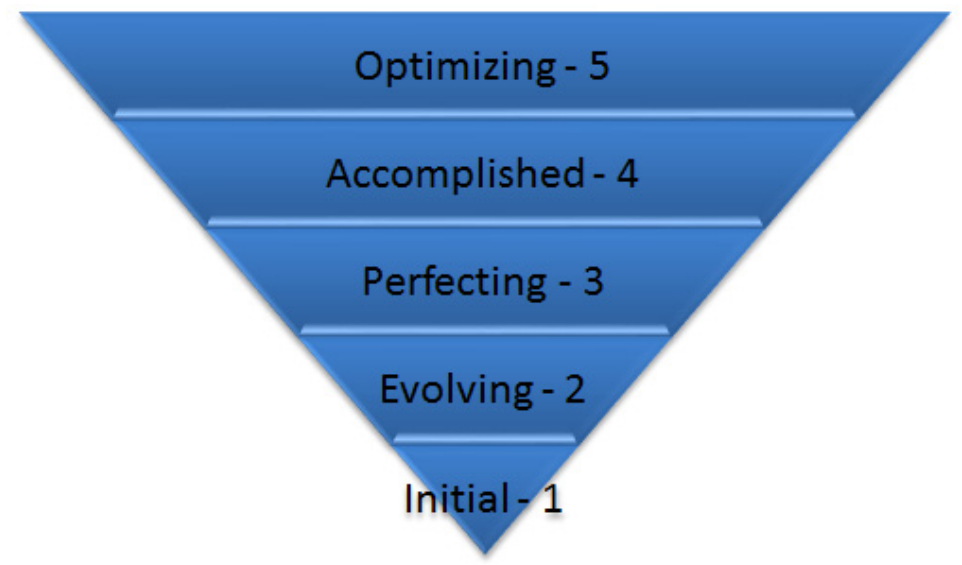

Figure 4. Five maturity levels proposed by Deloitte (see text for explanation) (source: own elaboration based on [14])

"1" (Initial) is a level featured by lack of standards or formal processes. " 2 " (Evolving) describes a level where some projects have developed best practice processes based on industry or consultant input and these processes are followed. However, the process is not routinely shared off project and has not been identified as standard. "3" (Perfecting) is a maturity level in which the organization is developing its own best practice standard and centrally controlled project management processes. "4" (Accomplished) means that best practice process has been developed and rolled out across the organization. " 5 " (Optimizing) - the highest level of maturity - describes that the best practice process has been rolled out across 
the organization and is being used on every applicable project. Project managers understand the process well, any problems that occur are resolved, and project feedback is provided on process improvement. In addition, the process has been optimized based on the project feedback and knowledge of industry best practices [14].

It is worth to underline that according to the Deloitte's report, overall result of the level of the construction project management maturity in Poland is 3,50 . The indicator is calculated as a weighted average of values (namely, maturity levels from 1 to 5) scaled by their importance (percentage of respondents selecting proper answer). Moreover, the indicator value of 3,50 implies that researched companies rate their project management maturity between "Perfecting" and "Accomplished" (explained earlier).

What is more interesting, maturity indicators differ from each other if we consider different revenue 2010 levels of the companies. While for a total revenue 2010 lower than 500 million zlotys (PLN), a maturity indicator is more or less the same $(3,43$, up to 150 million zlotys, and 3,44, from 150 to 500 million zlotys), for a total revenue 2010 over 500 million zlotys, a maturity indicator raises to 3,80 .
The most significant discovery is that the surveyed companies seems to be perfectly conditioned to deal with their projects and, therefore, displays the highest degree of maturity in terms of the Project Safety Management area. While three other areas, Project Quality Management, Project Procurement Management and Project Financial Management, are also featured by high level of maturity achieved by the construction companies (92\% and more respondents selected at least "Perfecting" level), those companies consider themselves less capable to deal with "Project Communication Management" - 24\% respondents marked Initial or Evolving level of maturity. The most reasonable conclusion of the survey results might be that companies try harder to develop their capabilities in terms of those areas that are officially introduced into law regulations. Occupational safety and health regulations, public procurement law, standardization like in particular quality standards (e.g., ISO) or some accounting regulations make companies improve their current practice (procedures, behavior, etc.), and at the same time, it gives them an opportunity to develop their maturity in these areas.

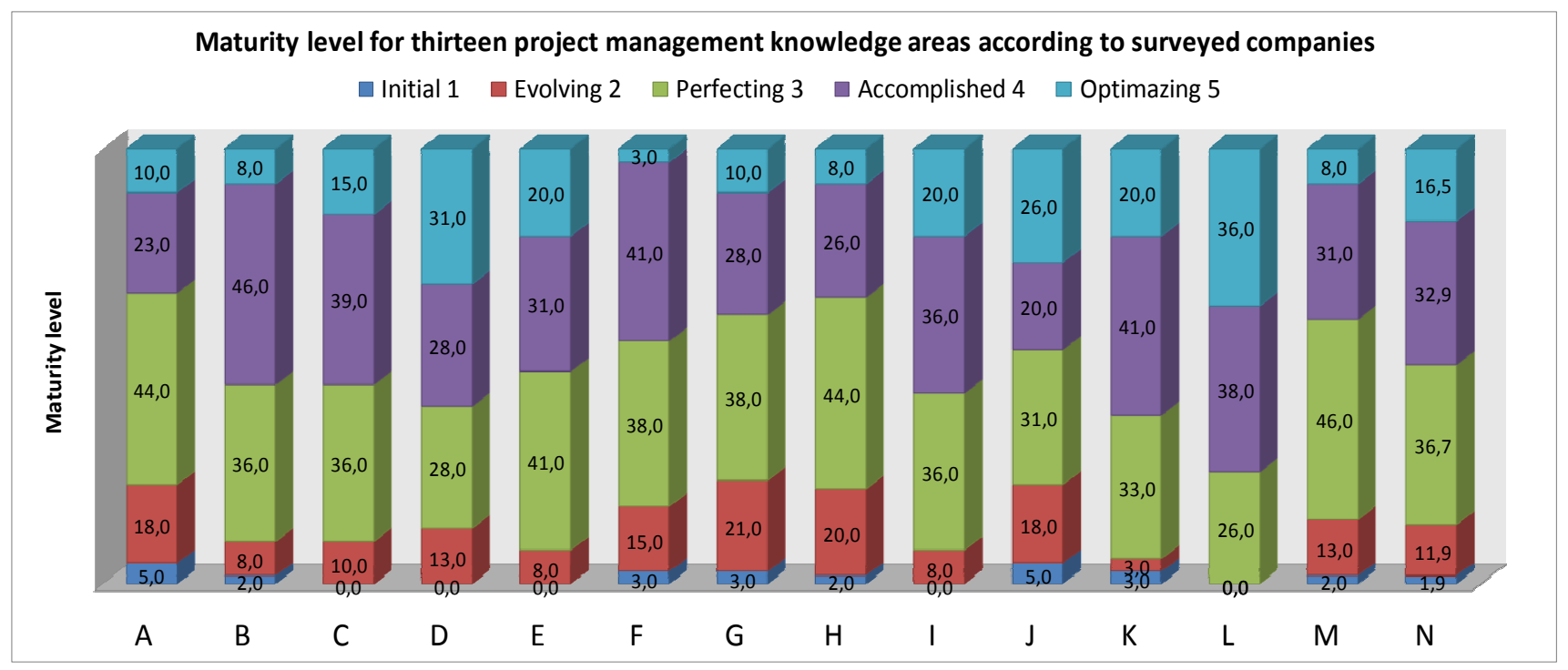

Figure 5. Maturity levels for 13 project management knowledge areas according to 39 polish construction companies (A, Project Integration Management; B, Project Scope Management; C, Project Time Management; D, Project Cost Management; E, Project Quality Management; F, Project Human Resource Management; G, Project Communication Management; H, Project Risk Management; I, Project Procurement Management; J, Project Environmental Management; K, Project Financial Management; L, Project Safety Management; M, Project Claim Management; N, Construction Project Management, overall scores), (source: own elaboration based on [14]) 
Literature review [15] recalls an explanation of the project maturity origins. A predecessor of this concept was process maturity created by Total Quality Management movement. A need for process maturity resulted from the efforts to reduce variability in the process and to improve its mean performance.

Since project management became popular and some PM methodologies were created and introduced into public, companies have been trying to understand their capabilities in project management and improve their procedures in accordance with the strategy and economic objectives.

Large-scale construction projects, such as skyscrapers, hub airports, and rail networks involve complex interfaces, varieties of stakeholders, and integration of materials and technologies, which incur uncertainties and associated risks. It has always been critically important and challenging for major stakeholders, such as clients and construction contractors to successfully manage the risk in those projects. Largescale construction projects are practically always connected with risk factors that generally lead to adverse impacts and costly consequences in project management [13].

First, it is worth to notice that there is a difference between price risk (mainly connected with commodity [16] and arising out of adverse movements in the world prices, exchange rates, and etc.) and cost risk that has some technological and organizational origins.

There are many definitions of cost risk that can be associated with a probability of loss owing to cost overrun [17]. Investigation of this phenomenon and the factors affecting cost overruns for the construction projects has attracted the interest of many researchers and practitioners [11]. That is why this problem is taken seriously more and more often. Although contemporary science knows basic principles of cost risk, there is still a necessity of searching for better solutions and more accurate methods of mitigating that kind of risk.

And what if there is no cost overrun as a consequence of, for example, cost underestimation but just the opposite? What if a plan was too pessimistic and real cost was lower than previously estimated? There is no loss (from one point of view, it might be a brilliant information) but still something goes wrong when cost estimation fails. No matter if it is underestimation or overestimation, it is always connected with poor project planning. More precisely, cost risk is the risk associated with the ability of the project to achieve the planned life-cycle costs. Thus, cost risk includes both design/construction and operating costs. John P. Kindinger and John L. Darby noticed that there are two major elements of cost risk: the accuracy and completeness of the cost estimates for the planned activities and the risk that cost performance will be affected adversely by a failure to manage technical risks, namely, those events or issues associated with the scope definition, research and development (R\&D), design, construction, and operation that could affect the actual level of performance versus that specified in the project mission need and performance requirements documents [18].

Apart from price risk and cost risk, it is significant to specify variety of risk factors in construction projects. There are more crucial like time-related risks $[19,20,21$, and 22], quality-related risks [19, 22], environment-related risks [19, 22], safety-related risks [19, 22, and 23], design drawing errors [19, 22], natural hazards $[19,22]$, and many others. In the following part of the article, some issues connected with human resource management and an impact of Generation $\mathrm{Y}$ on project maturity will be discussed.

\section{Generation $Y$ - chance or pitfall}

Generation gap between employees has been wellknown problem for ages [24]. But in the early 2000s, a brand new group of employees called Millennials (Millennial Generation, also known as Generation Y) became active on the labor market. This term was created in order to describe a group of people born from the early 1980 s to the early 2000 s. While those dates are rather approximate, the phrase Generation Y first appeared in an August 1993 Ad Age editorial to describe teenagers of the day, which they defined as different from Generation $\mathrm{X}$, and then aged 11 
or younger as well as the teenagers of the upcoming 10 years [25].

Since then, a phenomenon of Generation $\mathrm{Y}$ has attracted many sociologists and scientists carrying some research on the current problem connected with a suitability of the new group of employees in the organization.

\section{"Demography, not technology is creating the future" [26]}

According to some previous papers [24], it was revealed that project management is a convenient form of achieving business targets for the Millennials. Moreover, they are keen on being participants of the projects. Because a specificity of the construction industry enables to organize tasks to be like projects, management through projects can become a method of enterprise management. This may be used to profit from skills of the new generation.

Before superiors will be able to effectively manage Generation Y employees, they should first understand what Millennials are looking for in employment. They are not only at a different life stage to most managers, but they have been raised and educated in a unique environment, resulting in different job attitudes, working styles, and expectations of leaders. In particular, Generation Ys do not seek jobs as much as they seek opportunities - they recognize that work constitutes a major chunk of their life and, as such, should be as fulfilling as possible. In the current labor market, if the work is not living up to Generation Y's expectations, they can quickly and easily move on to bigger and better opportunities [26].

Some professionals maintain that Generation $\mathrm{Y}$ is not always an opportunity for the organization to build its competitive advantage but also a kind of challenge. Millennials have been spoiled by their parents, so probably they would feel appreciated if they were often rewarded for their efforts by employers $[24,27]$.

Moreover, it is significant to employ the best candidates, to manage them, and to retain successfully the most valuable Generation Y employees. To do so, managers should understand a sociological background affecting employees' behavior and then they should learn how to promote and foster some im- portant opportunities (e.g., professional growth and development, work-life balance, variety, social interaction, responsibility and input, reward and recognition) in all aspects of the employee life cycle [26]. All in all, Generation Y brings different values and attitudes to the workplace than some previous generations. However, these values and attitudes have their advantages and disadvantages.

In order for organizations to survive in the turbulent circumstances and remain competitive with this ever changing (and shrinking) workforce, they must adapt their people management practices to meet the needs of the up-and-coming generation of workers. Fighting this change will only make your business less competitive in the long term [26].

As a matter of fact, project managers in construction industry should adapt to new constraints by choosing a right way to change the organization. There are two different ways to adopt Generation Y employees into the company and profit from their skills and ability of working in projects, namely, evolutionary and revolutionary [24]. First attitude takes into account a present organizational culture and other values. On the other hand, the second one requires a deep reconstruction of the organization. In this case, skills of the Generation $\mathrm{Y}$ become a critical success factor for the company.

\section{Toward project maturity}

A recent survey was conducted by the author in 2013 among 18 foreign construction companies. The sample was established after having sent an online questionnaire to 60 construction companies from abroad. All respondents were experienced in construction management and were responsible for that in their companies. As a result, it was discovered that none of the companies were a micro or small enterprise. Majority of them were described as large enterprises employing 250-999 employees.

It is significant that $66 \%$ of the surveyed companies operated on the international market. Besides, respondents admitted that their business coverage can be described as regional (17\%) or country scale (17\%). Among the companies that participated in the survey, none of them was present on the local or global market. 


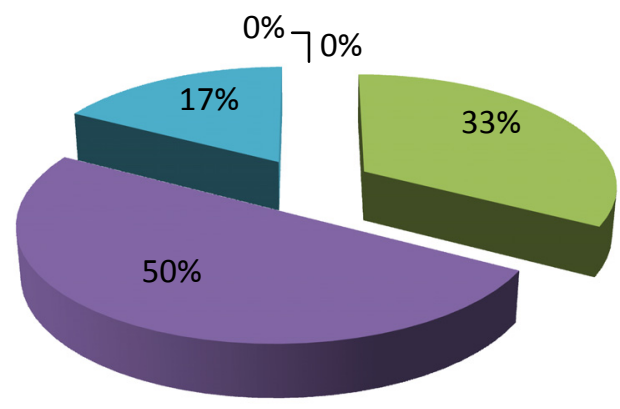

\author{
Micro enterprise \\ (employing 1-9 people) \\ Small enterprise (10-49) \\ Medium enterprise (50- \\ 249) \\ - Large enterprise (250- \\ 999) \\ Large enterprise (>1000)
}

Figure 6. Sample structure - size of the foreign construction companies (source: own elaboration)

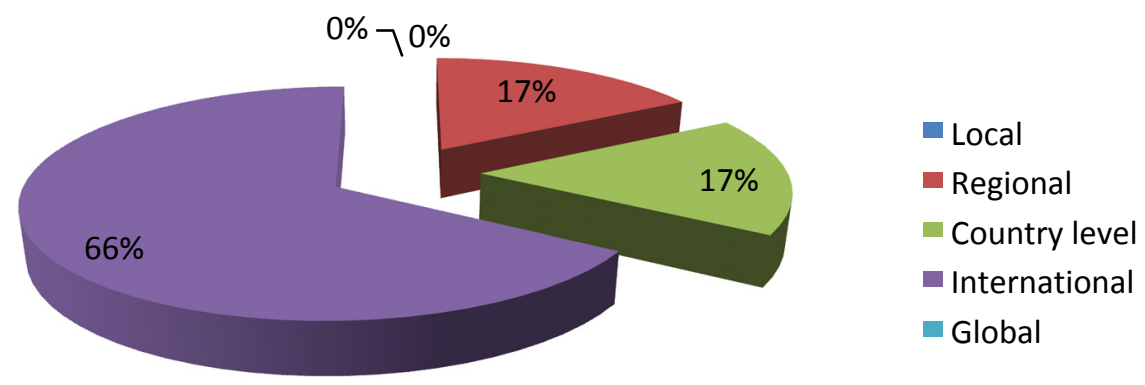

Figure 7. Sample structure - coverage of the foreign construction companies (source: own elaboration)

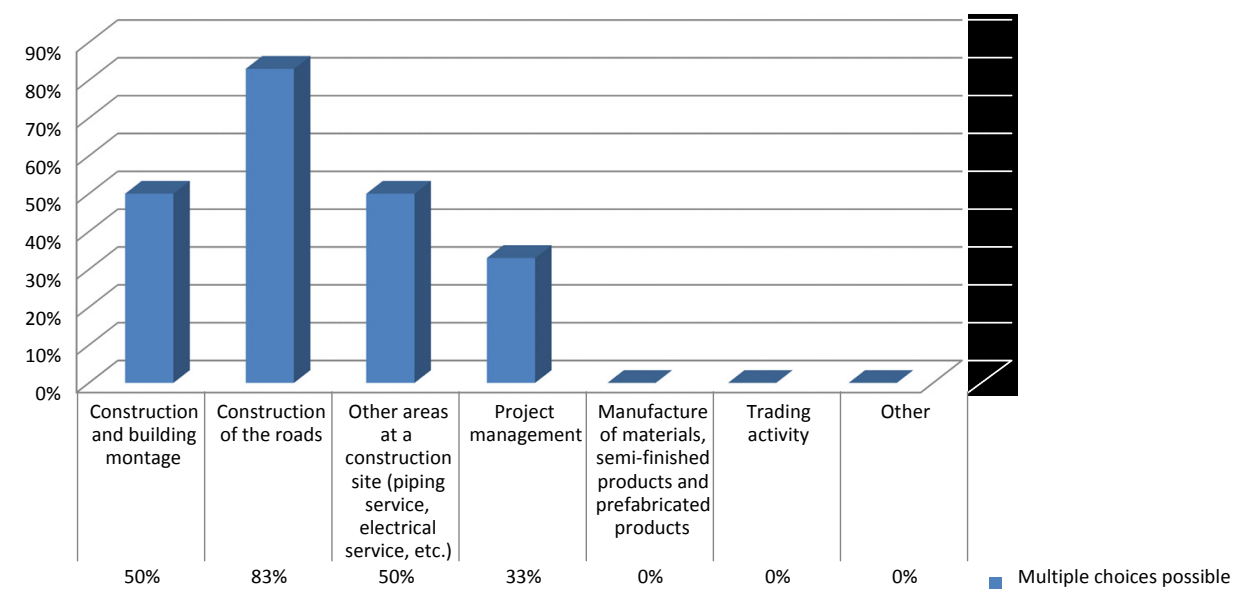

Figure 8. Sample structure - business activity areas (multiple choices possible) (source: own elaboration) 
Majority of the foreign construction companies answered that their main business activity area is construction of the roads.

Detailed results of the survey were presented in Fig. 6-7.

Fig. 9 presents types of organizational structure implemented by surveyed companies. While 33\% respondents maintain their company's functional organizational structure, the same number of them answered that there is a project organizational structure what can be a clear evidence for a higher project managers' awareness to create right conditions for project management. Furthermore, a project organizational structure that was perceived in one-third of surveyed companies can prove that they are more project matured than the others.

Fig. 10 brings a set of quite interesting remarks. Only $17 \%$ of respondents answered that their company has no official certified management system. The rest of the possible choices could be multiple, so $50 \%$ of the surveyed companies have both ISO 9000 and ISO 14000 management systems. Majority of the companies are equipped with some project management software (Fig. 11).

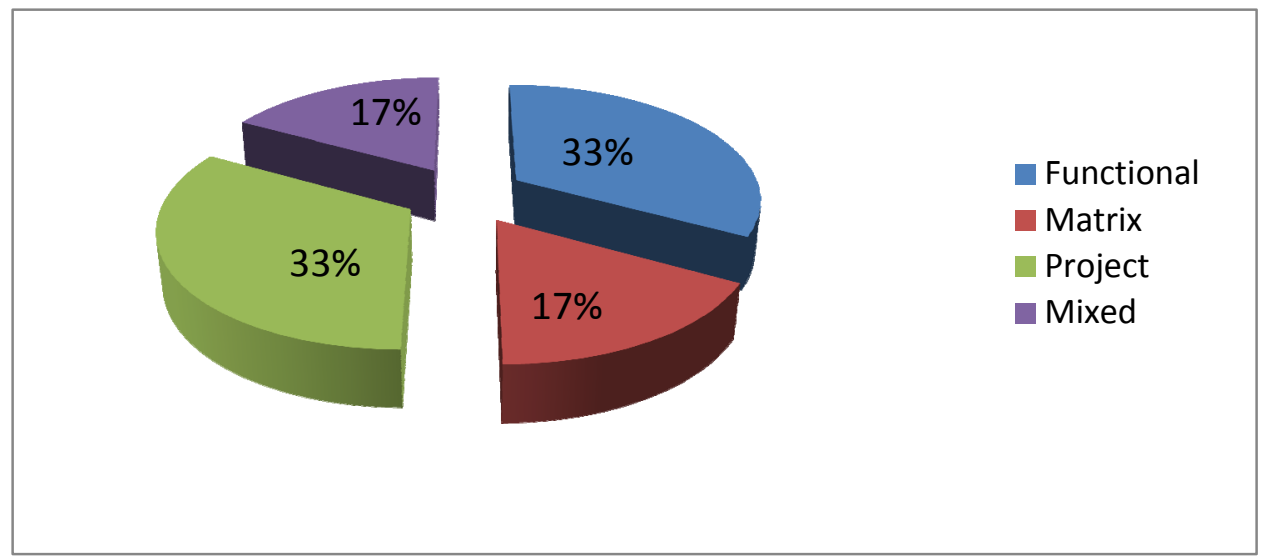

Figure 9. Types of organizational structure implemented by surveyed companies (source: own elaboration)

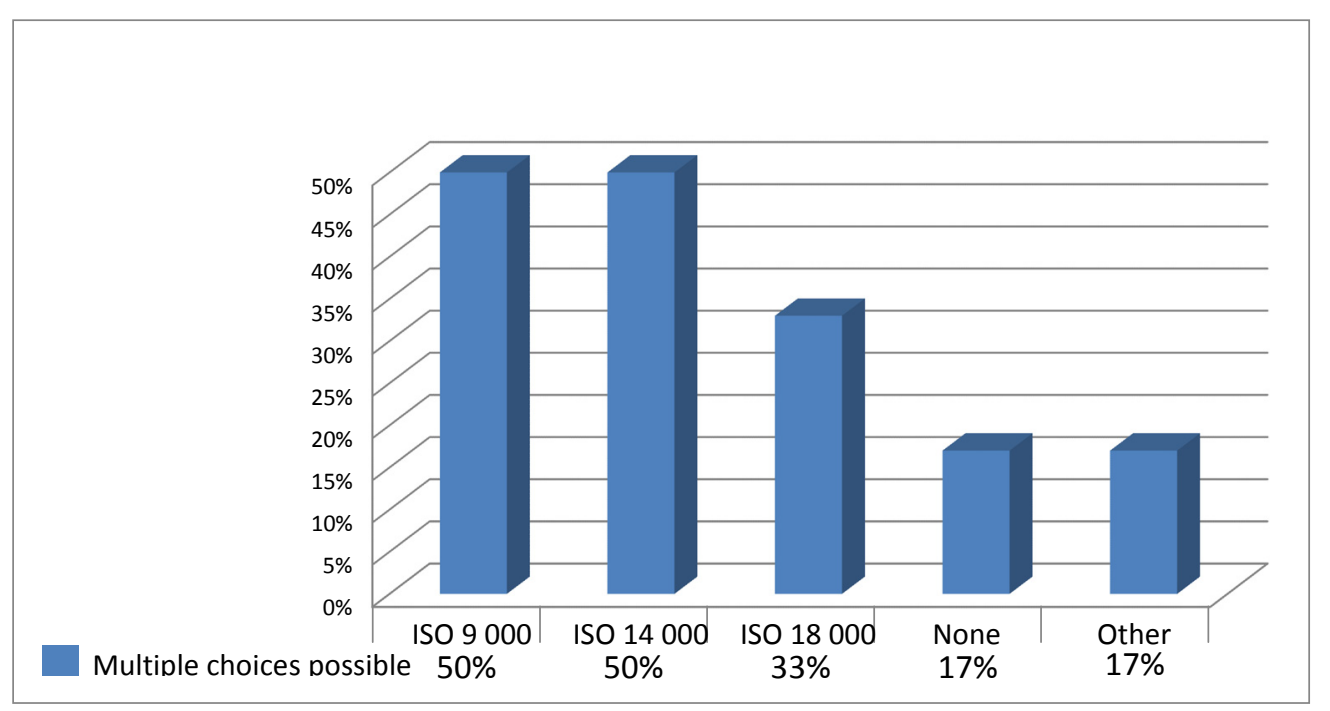

Figure 10. Sample structure - which certified management systems were implemented in the surveyed companies (multiple choices possible)

(source: own elaboration) 




Figure 11. Sample structure - if company uses some of the project management software (source: own elaboration)

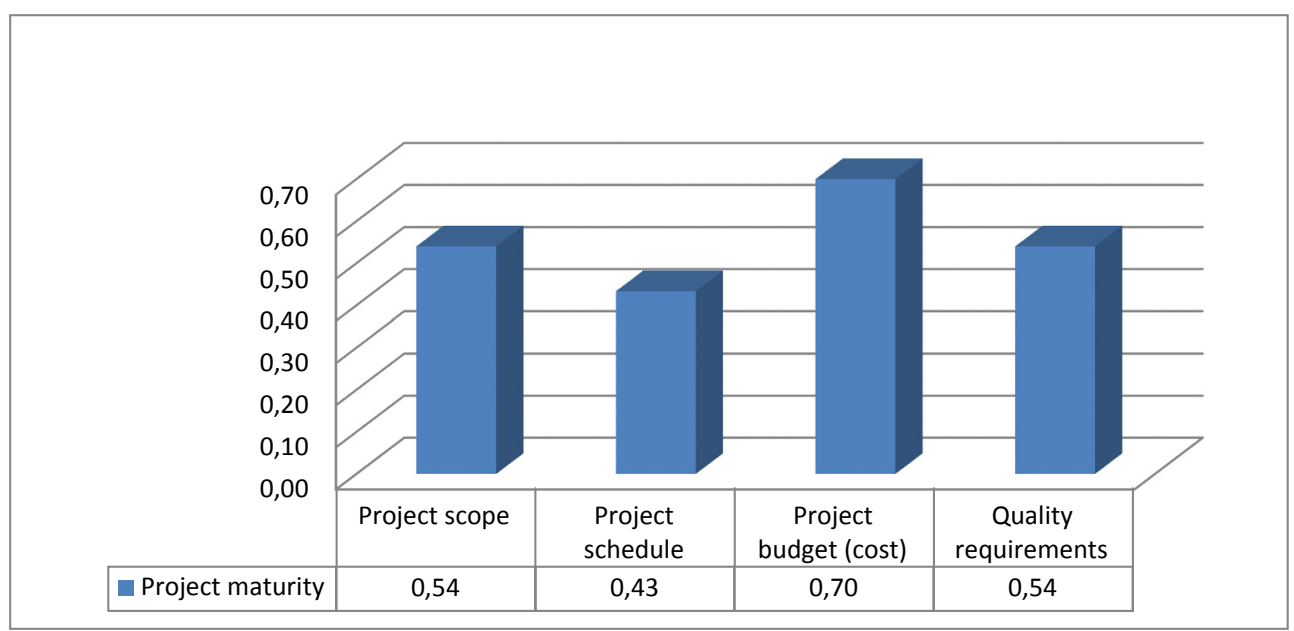

Figure 12. Project maturity of the surveyed construction companies according to the respondents (source: own elaboration)

In Fig. 12, the results of the project maturity calculation based on received answers and represented by four different areas of the project management are shown. Organizations that decided to participate in the survey were requested to indicate an average probability of planned four main factors (project scope, project schedule, project budget, and quality requirements) of the construction investment projects that have been executed by them.

The concept of project maturity was created as a weighted average of values (namely, an average probability of planned factors: $0.00-0.20,0.21-0.40$, $0.41-0.60,0.61-0.80$, and $0.81-1.00$ ) scaled by their importance (number of respondents selecting proper answer). Moreover, the indicator value of 1,0 implies that researched companies rate their project management maturity as perfect (fully matured organization), whereas 0,0 means an organization is not pro- project mature at all. Furthermore, there are three ranges of the indicator that classify three levels of project maturity: $0,00-0,33$ is low level of project maturity; 0,33-0,66 medium level of project maturity; and 0,66-1,00 high level of project maturity. Moreover, according to the survey, an overall score of project maturity among foreign construction companies was calculated as 0,55 (medium)

In Fig. 13, a perception (subjective interpretation) of respondents about project maturity of construction companies was presented. Majority of respondents maintained that their companies are quite matured (medium level) or matured (high level) in project management. Only $17 \%$ of respondents answered that their companies are rather less experienced in project management and, therefore, a project maturity level should be estimated as low. 


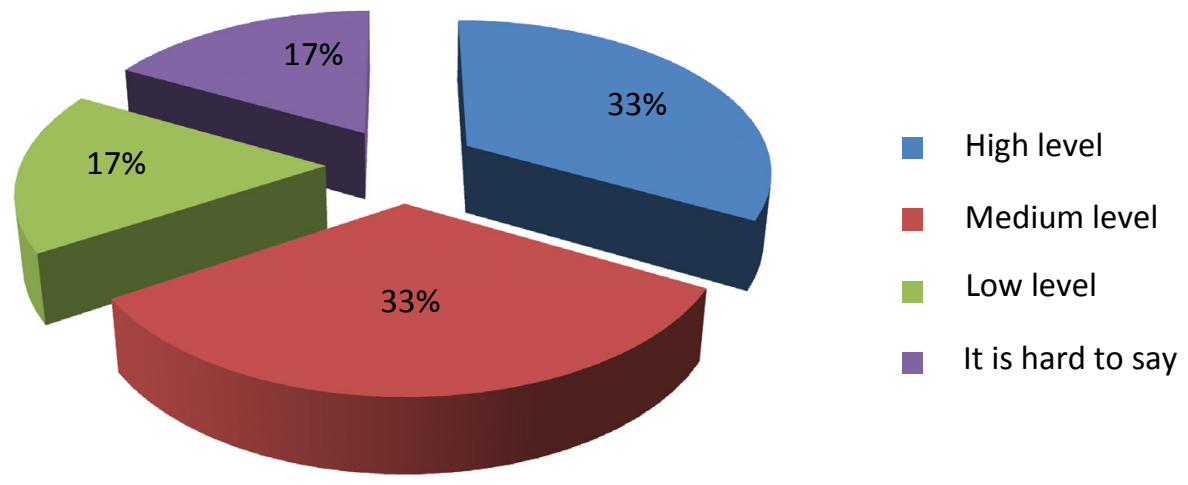

Figure 13. A perception about project maturity of the surveyed enterprises (source: own elaboration)

For the rest of them, the answer was quite difficult or a concept of project maturity was a little bit enigmatic. It is valuable to underline that a perception of respondents was given in accordance with a quantitative estimation of project maturity of the construction companies.

\section{Conclusion}

According to the results of surveys presented in the article, it was revealed that both Polish and foreign companies appreciate the value of project management. They see an importance of the continuous improvement of project management capabilities.

On the basis of some previous findings about project maturity, there is no doubt construction companies should try to improve their ability to manage projects. A need for improving the performance and perfecting the risk management can be a reason for creating a five-step model of continuous improvement of project maturity (Fig. 14).

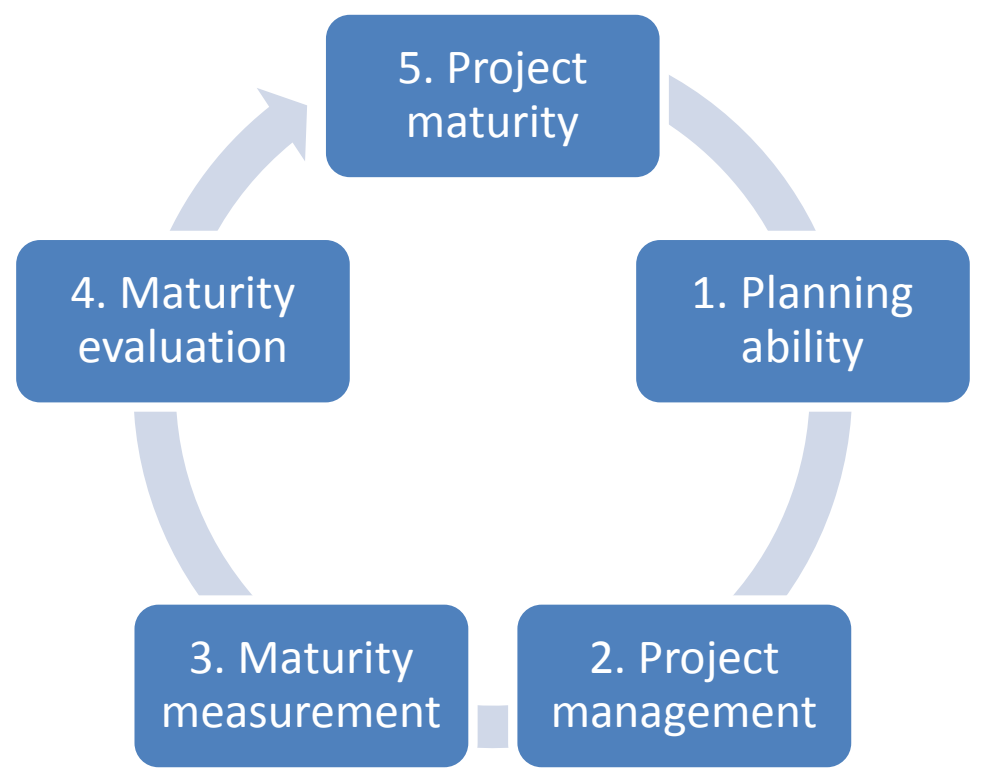

Figure 14. Cycle diagram - a five-step model of continuous improvement of project maturity (source: own work) 
It might be a solution for the companies to engage them into a constant pursuit of maturity. Indeed, it is a pursuit because as it was described earlier fully matured organization is just a theoretical concept.

Unfortunately, the survey did not touch a crucial issue - an aspect of Generation $\mathrm{Y}$ and their role in construction companies. A research on a role played by Generation Y employees in the construction company might be a good resolution for the future. While we know that Generation Y workforce revolution brought brand new circumstances and conditions for modern managers (Generation Y employees like no other group before are naturally predisposed to work in project organizational structure), there are some pitfalls coming from unique features of the new Generation. Supposedly, as soon as modern managers of construction companies are able to profit from skills of Generation Y, to employ and to retain the best of them, the companies will reach a competitive advantage so useful in turbulent economic environment.

\section{$7 \quad$ References}

[1] Atkinson R. - Project management: cost, time and quality, two best guesses and a phenomenon, its time to accept other success criteria [in] International Journal of Project Management Vol. 17, No. 6, 1999, pp. 337-342.

[2] Gardiner P.D., Stewart K. - Revisiting the golden triangle of cost, time and quality: the role of NPV in project control, success and failure [in] International Journal of Project Management 18, 2000, pp. 251-256.

[3] Newell M.W., Grashina M.N. - The Project Management Question and Answer Book. AMACOM, New York 2003.

[4] McGhee P., McAliney P. - Painless Project Management. A Step-By-Step Guide for Planning, Executing, and Managing Projects. John Wiley \& Sons, Inc., Hoboken, New Jersey 2007.

[5] Cobb C.G. - Making Sense of Agile Project Management. Balancing Control and Agility. John Wiley \& Sons, Inc., Hoboken, New Jersey 2011.
[6] Cleland D., Ireland L. - Project Manager's Handbook: Applying Best Practices Across Global Industries. The McGraw-Hill Companies, Inc., New York 2007.

[7] Project Management Institute, A Guide to the Project Management Body of Knowledge (PMBOK® Guide) - Fourth Edition. Project Management Institute, Inc., Newtown Square, Pennsylvania 2008, p. 7.

[8] Bizon-Górecka J., Górecki J. - Risk pyramid in the enterprise [in] Studies \& Proceedings of the Polish Association for Knowledge Management, No. 19. Polish Association for Knowledge Management, Bydgoszcz 2009, pp. 18-27.

[9] Zavadskas E.K., Turskis Z., Tamošaitiene J. Risk assessment of construction projects [in] Journal of Civil Engineering and Management, vol. 16, no. 1, 14 October 2010, pp. 33-46.

[10] Bizon-Górecka J. - The Risk Management Strategies in the Enterprise - Risk of an Enterprise and Risk of a Project, Scientific Society For Organization And Management Office Bydgoszcz, Bydgoszcz 2008.

[11] Górecki J. - From project success to the success of the construction enterprise [in] Papers and Reports of the Faculty of Management of Gdansk University, vol. 1, The Foundation for the Development of Gdańsk University, Sopot 2009, pp. 278-285.

[12] Edieb A.S. - DSS-PL: Decision Support System for Risk Assessment of Pipeline Projects [in] Cost Enineering, 11 November 2007, pp. 20-29.

[13] Andersen E.S., Jessen S.A. - Project maturity in organisations [in] International Journal of Project Management, vol. 21, August 2003, pp. 457-461.

[14] Jia G., Ni X., Chen Z., Hong B., Chen Y., Yang F., Lin C. - Measuring the maturity of risk management in large-scale construction projects [in] Automation in Construction, vol. 34, September 2013, pp. 56-66.

[15] Deloitte Poland. Member of Deloitte Touche Tohmatsu Limited - Polish construction companies 2012. Maturity of Construction Project Management, Deloitte Poland, 2012. 
[16] Cooke-Davies T.J., Arzymanow A. - The maturity of project management in different industries: An investigation into variations between project management models [in] International Journal of Project Management, vol. 21, August 2003, pp. 471-478.

[17] Claessens S., Duncan R.C. - Managing Commodity Price Risk in Developing Countries, The Johns Hopkins University Press, Baltimore and London 1993.

[18] BusinessDictionary.com - 2709 2012. [Online]. Available:

http://www.businessdictionary.com/definition/co st-risk.html.

[19] Kindinger J.P., Darby J.L. - Risk Factor Analysis - A New Qualitative Risk Management Tool [in] Proceedings of the Project Management Institute Annual Seminars \& Symposium, Houston, Texas 2000 .

[20] Kuo Y.-C., Lu S.-T. - Using fuzzy multiple criteria decision making approach to enhance risk assessment for metropolitan construction projects [in] International Journal of Project Management, vol. 31, May 2013, pp. 602-614.

[21] Taroun A. - Towards a better modelling and assessment of construction risk: Insights from a literature review [in] International Journal of Project Management, vol. 32, January 2014, pp. 101-115.

[22] Luu V.T., Kim S.-Y., Tuan N.V., Ogunlana S.O. - Quantifying schedule risk in construction projects using Bayesian belief networks [in] International Journal of Project Management, vol. 27, January 2009, pp. 39-50.
[23] Hwang B.-G., Zhao X., Shu Gay M.J. - Public private partnership projects in Singapore: Factors, critical risks and preferred risk allocation from the perspective of contractors [in] International Journal of Project Management, vol. 31, April 2013, pp. 424-433.

[24] Aminbakhsh S., Gunduz M., Sonmez R. - Safety risk assessment using analytic hierarchy process (AHP) during planning and budgeting of construction projects [in] Journal of Safety Research, vol. 46, September 2013, pp. 99-105.

[25] Górecki J. - Pokolenie Y wyzwaniem dla organizacji [in] Uwarunkowania sukcesu organizacji (ed. H. Czubasiewicz, Z. Mokwa and P. Walentynowicz). Fundacja Rozwoju Uniwersytetu Gdańskiego, Gdańsk 2013, pp. 189-199.

[26] wikipedia.org [Online]. Available: http://en.wikipedia.org/wiki/Millennials. [Accessed 1401 2014].

[27] Urwin R. - Generation Y. Attracting, engaging and leading a new generation at work. Drake International, 2006. [Online]. Available: http://hrinsider.ca/wpcontent/uploads/2014/01/white_papergeneration_y.pdf. [Accessed 1401 2014].

[28] Van den Bergh J., Behrer M. - Jak kreować marki, które pokocha pokolenie Y? Samo Sedno, Warszawa 2012. 